\title{
Role of Capsaicin in the Repair of Cellular Activity in Mice Liver
}

\author{
Mohammad Sukmanadii ${ }^{1}$, Mustofa Helmi Effendii ${ }^{2, *}$, Faisal Fikri ${ }^{3}$, Muhammad Thohawi Elziyad Purnama $^{4}$
}

\begin{abstract}
Mohammad Sukmanadi ${ }^{1}$, Mustofa Helmi Effendi ${ }^{2, *}$, Faisal Fikri ${ }^{3}$, Muhammad Thohawi Elziyad Purnama ${ }^{4}$

'SubDivision of Veterinary Pharmacy, Division of Veterinary Basic Science, Faculty of Veterinary Medicine, Universitas Airlangga, Surabaya, INDONESIA.

${ }^{2}$ Division of Veterinary Public Health, Department of Veterinary Science, Faculty of Veterinary Medicine, Universitas Airlangga, Surabaya, INDONESIA.

${ }^{3}$ SubDivision of Veterinary Pharmacology, Division of Veterinary Basic Science, Faculty of Veterinary Medicine, Universitas Airlangga, Surabaya, INDONESIA.

${ }^{4}$ Division of Veterinary Anatomy, Department of Veterinary Science, Faculty of Veterinary Medicine, Universitas Airlangga, Surabaya, INDONESIA.
\end{abstract}

\section{Correspondence}

\section{Mustofa Helmi Effendi}

Division of Veterinary Public Health, Department of Veterinary Science, Faculty of Veterinary Medicine, Universitas Airlangga, Surabaya, INDONESIA.

E-mail: mheffendi@yahoo.com

History

- Submission Date: 14-09-2021;

- Review completed: 10-10-2021;

- Accepted Date: 14-10-2021.

\section{DOI : 10.5530/pj.2021.13.201}

Article Available online

http://www.phcogj.com/v13/i6

\section{Copyright}

(c) 2021 Phcogj.Com. This is an openaccess article distributed under the terms of the Creative Commons Attribution 4.0 International license.

\begin{abstract}
This study aimed to determine the capsaicin efficacy on Kupffer cell, polymorphonuclear, stellate, and fibroblast cells in mice liver induced with aflatoxin B1. A total of 20 mice were used as sample, assigned into four group i.e. (T0) administered $0,5 \mathrm{ml}$ of polyethylene glycol, (T1) administered $0,5 \mathrm{ml}$ of capsaicin $+0,5 \mathrm{ml}$ of polyethylene glycol, (T2) administered $0,1 \mathrm{ml}$ of aflatoxin B1 $+0,5 \mathrm{ml}$ of polyethylene glycol, (T3) administered $0,1 \mathrm{ml}$ of aflatoxin B1 $+0,5 \mathrm{ml}$ of capsaicin, respectively. All treatment were done for a month then followed by liver dissection for hematoxylin eosin staining. The differential cells counted then analyzed using ANOVA and Tukey multiple comparison test $(p<0,05)$. The cell determination showed that Kupffer cell, polymorphonuclear, stellate, and fibroblast cells decreased significantly $(p<0,05)$ in T3 group compared to T2 group. Meanwhile, the T1 group showed similar $(p>0,05)$ with T0 group. It can be concluded that capsaicin has a potential effect to improve cellular activity in mice liver with aflatoxin B1 toxication.
\end{abstract}

Key words: Aflatoxin B1, Animal, Capsaicin, Kupffer cell, Stellate, Fibroblast.

\section{INTRODUCTION}

Mycotoxins are secondary metabolites produced by fungi that can cause disease in humans and animals. Several mycotoxins or mycotoxin derivatives have been found to have pharmacological activity and are used as antibiotics and growth promoters ${ }^{1}$. Aflatoxin is a natural contaminant produced by several species of Aspergillus which is commonly found in hot and humid climates, especially at temperatures of $27-40^{\circ} \mathrm{C}\left(80-104^{\circ} \mathrm{F}\right)$ and a relative humidity of $85 \%{ }^{2}$. The most common Aspergillus found were A. flavus which produces aflatoxin B, and $A$. parasiticus which produces aflatoxins $B$ and G. Aflatoxin M1 and M2 are metabolites resulting from the hydroxylation of aflatoxins B1 (AFB1) and B2 (AFB2) by cytochrome p450-1A2 in humans or animals that consume food contaminated with aflatoxins ${ }^{3}$.

Metabolism of the toxin after ingestion by animals, the toxin is transformed into different metabolites with different levels of toxicity. Some metabolites can accumulate in the body, while others are excreted. The most toxic metabolite is 8,9 -epoxideAFB1, which binds to DNA and RNA ${ }^{4}$. The biotransformation process that occurs in the liver is an important initial stage for aflatoxins. Aflatoxins undergo bioactivation after going through a biotransformation process so that they are radical, toxic and have a hepatotoxic effect ${ }^{5}$. Aflatoxin biotransformation process begins with oxidation in cytochrome $\mathrm{p} 450$ and then produces various aflatoxin metabolites with toxicity levels not lower than the initial compound ${ }^{6}$.

Recent studies of disease-related capsaicin activity, capsaicin exerts beneficial effects on analgesic function, cardiovascular system, diabetes, gastroprotection, urogenital disorders and weight loss $^{7}$. On the other hand, the transient receptor potential cation channel subfamily $\mathrm{V}$ member 1 (TRPV1) needs further investigation ${ }^{8}$. Capsaicin has shown beneficial effects and confirmation of its efficacy is needed. This study evaluated the effect of capsaicin on the Kupffer cells, stellate, polymorphonuclear (PMN), and fibroblasts in the mice liver with AFB1-induction.

\section{MATERIALS AND METHODS}

\section{Ethical approval}

This research was approved by the Laboratory Animal Ethics Committee, Faculty of Veterinary Medicine, Airlangga University with certificate No. No. 1. KE. 198. 12. 2019. This approval prevents animal abuse and animal stress during treatment.

\section{Experimental design}

A total of 100 gram chili were extracted using rotary evaporator then incubated prior the treatment. The capsaicin was purified using highly performance liquid chromatography ${ }^{9}$. Acclimatization in mice was carried out for a week. A total of 20 mice were used as sample, divided into four group i.e. (T0) administered $0,5 \mathrm{ml}$ of polyethylene glycol, (T1) administered $0,5 \mathrm{ml}$ of capsaicin $+0,5 \mathrm{ml}$ of polyethylene glycol, (T2) administered $0,1 \mathrm{ml}$ of aflatoxin $\mathrm{B} 1+0,5 \mathrm{ml}$ of polyethylene glycol, (T3) administered $0,1 \mathrm{ml}$ of aflatoxin $\mathrm{B} 1+0,5$ $\mathrm{ml}$ of capsaicin, respectively. All treatments were carried out for one month and then the mice were euthanized with cervical dislocation. Liver organs were preserved and fixed for hematoxylin eosin staining.

\section{Cellular observations in the liver}

Briefly, the liver was immersed in $10 \%$ neutral buffer formalin solution and then dissected. Then the dehydration process was carried out in graded alcohol concentrations, i.e. $70 \%, 80 \%, 90 \%$ alcohol, each for 2 hours. Then it was cleared with xylol then printed using paraffin so that the preparations were printed in paraffin blocks and stored in the 


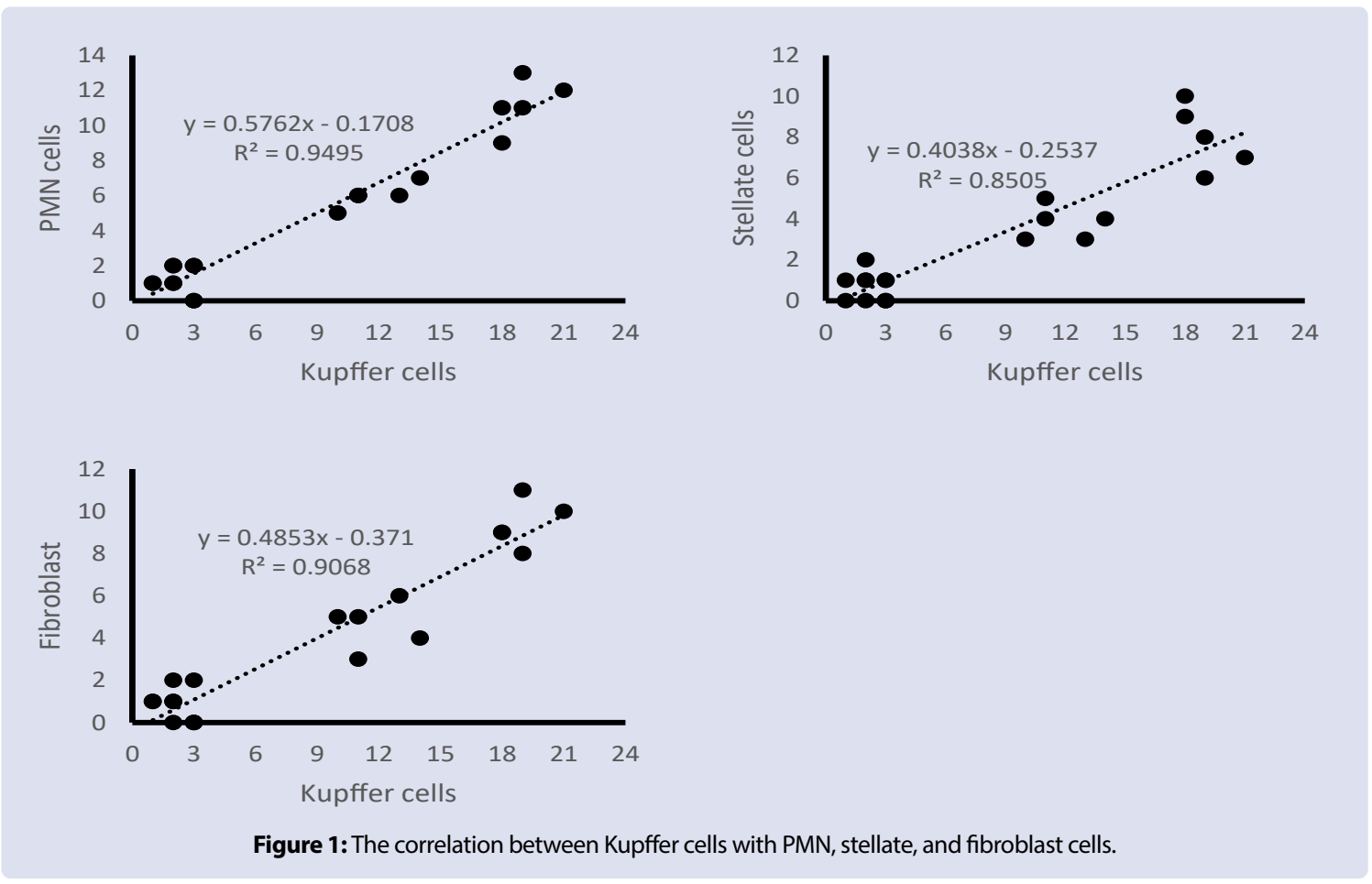

Table 1. The cell determination in liver during treatment.

\begin{tabular}{ccccc}
\hline Group & Kupffer cells & PMN cells & Stellate cells & Fibroblast \\
T0 & $2,0 \pm 1,00^{\mathrm{a}^{* * * *}}$ & $1,0 \pm 0,71^{\mathrm{a}^{* * * *}}$ & $0,6 \pm 0,55^{\mathrm{a}, * * *}$ & $0,6 \pm 0,55^{\mathrm{a}^{, * * *}}$ \\
T1 & $2,4 \pm 0,55^{\mathrm{a}, * * *}$ & $1,4 \pm 0,89^{\mathrm{a}, * * *}$ & $0,8 \pm 0,84^{\mathrm{a}, * * *}$ & $1,0 \pm 1,00^{\mathrm{a}, * * *}$ \\
T2 & $19,0 \pm 1,22^{\mathrm{c}}$ & $11,2 \pm 1,48^{\mathrm{c}}$ & $8,0 \pm 1,58^{\mathrm{c}}$ & $9,4 \pm 1,14^{\mathrm{c}}$ \\
T3 & $11,8 \pm 1,64^{\mathrm{b}, * * *}$ & $6,0 \pm 0,71^{\mathrm{b}, * * *}$ & $3,8 \pm 0,84^{\mathrm{b}, * * *}$ & $4,6 \pm 1,14^{\mathrm{b}, * * *}$
\end{tabular}

Values are expressed in mean \pm standard deviation ( $n=5$ animals for each four groups). One-way analysis of variance was carried out followed by post hoc Tukey multiple comparisons test. Values are represented statistically when ${ }^{\mathrm{a}, \mathrm{b}, \mathrm{c}}$ in comparison with the T0 group; ${ }^{*}<0.05,{ }^{* *}<0.01$, and ${ }^{* *}<0.001$, in comparison with the T2 group.

refrigerator. The paraffin blocks were then cut into thin strips of 5-6 m using a microtome. The pieces were floated in warm water at $60 \mathrm{oC}$ for 24 hours. The preparation was then removed and placed in an object glass for hematoxylin eosin staining. Observation of the number of Kupffer cells, stellate, PMN, and fibroblasts were examined under a microscope ${ }^{10}$.

\section{Data analysis}

Data are represented as mean \pm standard deviation. All variables were analyzed using ANOVA followed by a post hoc Tukey multiple comparison test $(\mathrm{p}<0.05)$. The association between Kupffer cells with stellate, PMN and fibroblasts was analyzed by linear regression.

\section{RESULTS}

The results of the evaluation of the number of Kupffer cells, stellate, PMN and fibroblasts showed a significant decrease $(\mathrm{p}<0.05)$ in the T3 group compared to the T2 group, respectively. Meanwhile, the T1 group was similar $(\mathrm{p}>0,05)$ to the T0 group. On the other hand, Kupffer cells were revealed to be positively correlated with an increase in stellate $\left(y=0,5762 x-0,1708 ; R^{2}=0,9495\right), P M N\left(y=0,4038 x-0,2537 ; R^{2}=\right.$ $0,8505)$, and fibroblasts $\left(y=0,4853 x-0,371 ; R^{2}=0,9068\right)$.

\section{DISCUSSION}

The results of this study on the protective effect of Capsaicin, counted the Kupffer cells, stellate, PMN and fibroblasts. Aflatoxins are mycotoxins that receive great attention in food safety, because of their wide distribution in food and feed, as well as their high toxicity, chemical hazards that contribute greatly to the high incidence of aflatoxicosis ${ }^{11}$. This toxicological aspect is a prerequisite for the design of curative or preventive means, and regulates the suitability of occurrence in food and feed. Although aflatoxins are mainly associated with cancer, it is now widely studied and it is known that AFB1 causes various other acute and chronic diseases ${ }^{12}$. AFB1 has long been associated with the liver, where it is first metabolized to release reactive secondary metabolites. In the case of aflatoxin B1 (AFB1), the known secondary metabolite aflatoxin is AFB1-8,9-epoxide, which is formed as the initial metabolism of AFB1 by the cytochrome microsomal enzyme (CYP450), considered to be the oxidant most responsible for genotoxicity ${ }^{13}$. Evidence that increased oxidative stress induced by AFB 1 plays an equal or even higher role in aflatoxin genotoxicity, toxicological effects and mechanism of action of aflatoxins ${ }^{14}$.

This hepatic impairment can be compensated by plasma membrane sodium, which relies on the $\mathrm{Na}+\mathrm{K}+$-ATPase pump to remove sodium from the cell ${ }^{15}$. Harmful agents can interfere with these membraneregulated processes by increasing plasma permeability to $\mathrm{Na}+$ thereby exceeding the pump's capacity to expel ions, damaging the pump directly, or interfering with ATP synthesis. The accumulation of sodium in the cell causes an increase in intracellular water to maintain isosmotic conditions and then the cell swells ${ }^{16}$. Many inflammatory cells have a negative effect on liver function. Inflammatory cells can normally be found in the hepatic vein area because they are lymphoid follicles as a defense in the hepatic portal area in certain numbers, the presence of necrosis and apoptosis of hepatocytes, and the presence of 
inflammatory cells such as neutrophils, lymphocytes, and plasma cells which indicate the occurrence of acute hepatitis ${ }^{17}$.

Histopathological features of the liver in normal conditions are seen sinusoidal hepatocytes with central veins and portal tracts arranged concentrically ${ }^{18}$. The portal tract consists of the portal triad which includes the hepatic artery, portal vein, and bile duct ${ }^{19}$. However, diabetic mice showed changes in the arrangement of cells around the central vein, periportal fat infiltration, and focal necrosis of hepatocytes ${ }^{20}$. Capsaicin can inhibit cytokine transcription, the mechanism may be through the reduction of intracellular reactive oxygen species ${ }^{21}$. Capsaicin will reduce pro-inflammatory cytokines, namely interleukin-1. Thus, capsaicin can reduce the average number of Kupffer cells $\mathrm{s}^{22}$. Isolation and identification of plant active compounds and standardized doses play an important role in increasing the hypoglycemic activity of herbal plants ${ }^{23}$.

In this study, the oral administration of capsaicin from chili was tested and the results showed a gradual decrease in the number of PMN cells and fibroblasts in the T3 group compared to the T2 group. The process of cell regeneration takes place immediately after tissue injury occurs. Then macrophages replace PMN cells as the main cells and play an important role in regeneration ${ }^{24}$. Liver fibrosis is a common pathological consequence of chronic liver disease which is characterized by the progressive formation of scar tissue in the liver parenchyma as a response to wound healing due to chronic injury. Liver fibrosis is an outcome of all chronic liver injury, with manifestations of extracellular matrix protein deposition resulting in scar tissue at the site of injury, loss of tissue architecture and liver failure ${ }^{25}$. Chronic injury can be caused by infection with Hepatitis B or C virus, parasitic infection, alcohol, drugs and toxins, venous obstruction, cholestasis, autoimmune or metabolic diseases such as obesity. Fibrosis that continues can end up as cirrhosis ${ }^{26}$.

The onset of liver fibrosis is usually unknown and undetectable. Morbidity and mortality occur after fibrosis progresses to cirrhosis, and generally progression to cirrhosis occurs after an interval of 15-20 years ${ }^{27}$. This progression occurs more rapidly in some settings, such as episodes of severe acute alcoholic hepatitis, subfulminant hepatitis and cholestatic fibrosis in patients with HCV reinfection after liver transplantation ${ }^{28}$.

\section{CONCLUSIONS}

In conclusion, capsaicin had an effect to ameliorate Kupffer cell, PMN, stellate, and fibroblast cells in mice liver induced with AFB1.

\section{ACKNOWLEDGMENTS}

The authors thank to Faculty of Veterinary Medicine, Universitas Airlangga for provide support this study through scheme Penelitian Dasar Disertasi (PDD) with grant No. 419/UN3.15/PT/2021.

\section{DECLARATION OF INTEREST}

The authors report no conflicts of interest.

\section{REFERENCES}

1. Anfossi L, Giovannoli C, Baggiani C. Mycotoxin detection. Current opinion in biotechnology, 2016; 37: 120-126.

2. Kamei K, Watanabe A. Aspergillus mycotoxins and their effect on the host. Medical mycology, 2005; 43.Supplement_1: S95-S99.

3. Rawal S, Kim JE, Coulombe Jr R. Aflatoxin B1 in poultry: Toxicology, metabolism and prevention. Research in veterinary science, 2010; 89.3: 325-331.

4. Marchese S. Aflatoxin B1 and M1: Biological properties and their involvement in cancer development. Toxins, 2018; 10.6: 214.
5. Dai Y. Aflatoxin B1-induced epigenetic alterations: An overview. Food and Chemical Toxicology, 2017; 109: 683-689.

6. Rushing BR, Selim MI. Aflatoxin B1: A review on metabolism, toxicity, occurrence in food, occupational exposure, and detoxification methods. Food and chemical toxicology, 2019; 124: 81-100.

7. Effendi $M H$, Sukmanadi M. Analysis of Capsicum annuum $L$. Methanolic Extract and Its Potential as a Hepatoprotector. Indian Journal of Forensic Medicine \& Toxicology, 2021; 15.3: 3679.

8. Sukmanadi M, Sudjarwo SA, Effendi MH. Molecular Mechanism of Capsaicin from (Capsicum Annuum L.) on Expression of MAPK1 And AKT1 Protein as Candidate of Anticancer Drugs: In Silico Study. Pharmacognosy Journal, 2020, 12.4.

9. Nadi MS, Fikri F, Purnama MTE. Determination of Capsaicin Levels in Capsicum annum Linn Ethanolic Extract using Thin Layer Chromatography Analysis. Drugs, 2020; 70.14: 1831-1842.

10. Giacomelli MG, et al. Virtual hematoxylin and eosin transillumination microscopy using epi-fluorescence imaging. PLoS One, 2016; 11.8 e0159337.

11. Verheecke C, Liboz T, Mathieu F. Microbial degradation of aflatoxin B1: current status and future advances. International journal of food microbiology, 2016; 237: 1-9.

12. Monson MS, Coulombe RA, Reed KM. Aflatoxicosis: Lessons from toxicity and responses to aflatoxin B1 in poultry. Agriculture, 2015; 5.3: $742-777$

13. Xue $Z$, et al. Recent advances in aflatoxin B1 detection based on nanotechnology and nanomaterials-A review. Analytica chimica acta, 2019; 1069: 1-27.

14. Deng J, et al. Aflatoxin B1 metabolism: regulation by phase I and II metabolizing enzymes and chemoprotective agents. Mutation research/reviews in mutation research, 2018; 778: 79-89.

15. Titchenell PM, Lazar MA, Birnbaum MJ. Unraveling the regulation of hepatic metabolism by insulin. Trends in Endocrinology \& Metabolism, 2017; 28.7: 497-505

16. Trefts E, Williams AS, Wasserman DH. Exercise and the regulation of hepatic metabolism. Progress in molecular biology and translational science, 2015; 135: 203-225.

17. Trefts E, Williams AS, Wasserman DH. Exercise and the regulation of hepatic metabolism. Progress in molecular biology and translational science, 2015; 135: 203-225.

18. Cvitanović TT, et al. LiverSex computational model: sexual aspects in hepatic metabolism and abnormalities. Frontiers in physiology, 2018; 9: 360 .

19. Sharabi K, Tavares CD, Puigserver P. Regulation of hepatic metabolism, recent advances, and future perspectives. Current diabetes reports, 2019; 19.10: 1-7.

20. Purnama MTE, et al. Serum liver enzyme profile in Timor deer (Cervus timorensis) with fascioliasis in Indonesia. Tropical Biomedicine, 2021; 38.1: 57-61.

21. Sinha RA, Singh BK, Yen PM. Direct effects of thyroid hormones on hepatic lipid metabolism. Nature Reviews Endocrinology, 2018; 14.5 259-269.

22. Oleaga $C$, et al. Investigation of the effect of hepatic metabolism on off-target cardiotoxicity in a multi-organ human-on-a-chip system. Biomaterials, 2018; 182: 176-190.

23. Cartus AT, et al. Hepatic metabolism of carcinogenic $\beta$-asarone. Chemical research in toxicology, 2015; 28.9: 1760-1773.

24. Liu $X$, et al. Hepatic metabolism in liver health and disease. In: Liver Pathophysiology. Academic Press, 2017; p. 391-400.

25. Saxena NK, Anania FA. Adipocytokines and hepatic fibrosis. Trends in Endocrinology \& Metabolism, 2015; 26.3: 153-161. 
26. Suryadiningrat $M$, et al. Dietary polyvinyl alcohol and alginate nanofibers ameliorate hyperglycemia by reducing insulin and glucosemetabolizing enzyme levels in mice with streptozotocin-induced diabetes. Veterinary World, 2021; 14.4: 847.

27. Trautwein $\mathrm{C}$, et al. Hepatic fibrosis: concept to treatment. Journal of hepatology, 2015; 62.1: S15-S24.
28. Kamal S, et al. Beneficial effects of statins on the rates of hepatic fibrosis, hepatic decompensation, and mortality in chronic liver disease: a systematic review and meta-analysis. Official journal of the American College of Gastroenterology| ACG, 2017; 112.10: 14951505.

\section{GRAPHICAL ABSTRACT}

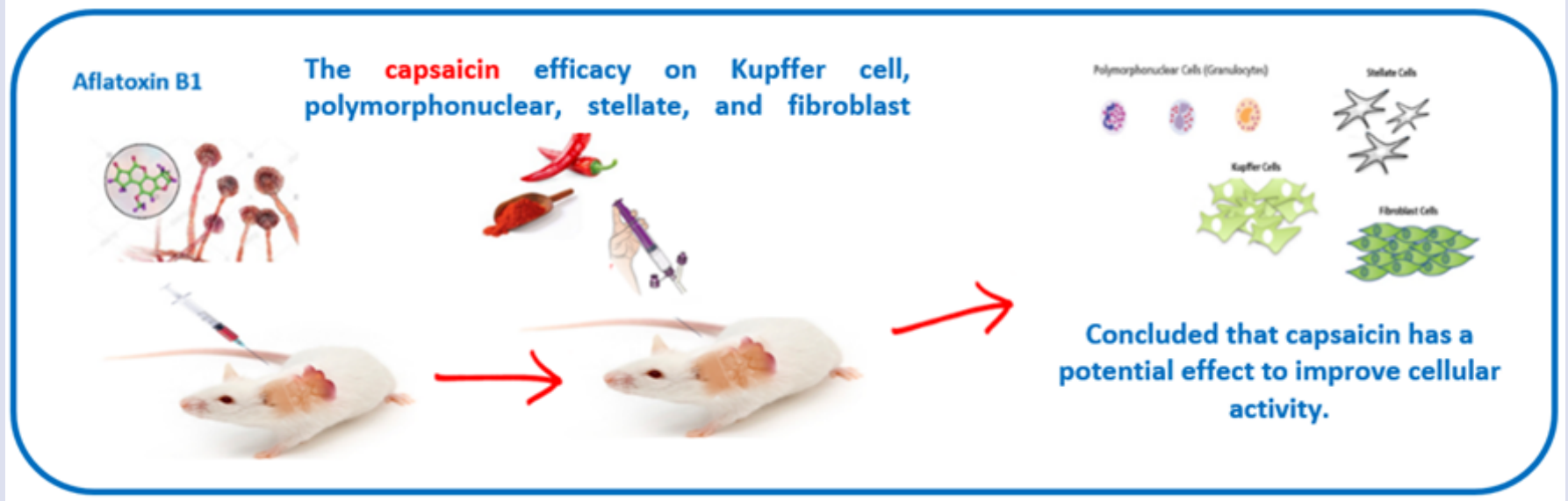

\section{ABOUT AUTHORS}
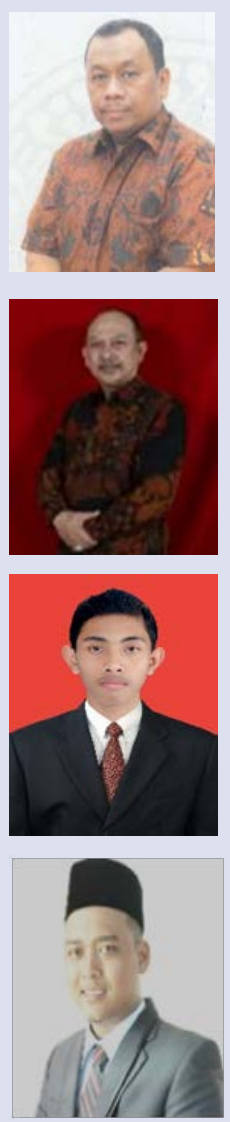

Dr. Mohammad Sukmanadi, DVM, MSc., Doctoral in Veterinary Science, Lecturer, Researchers; Veterinary Pharmacy Subdivision, Veterinary Basic Science Division, Faculty of Veterinary Medicine, Universitas Airlangga, Surabaya, Indonesia. His research focus is in the fields of Veterinary Pharmacy, Herbal Medicine, biomaterials and animal ethics. A total of 12 publications indexed by SCOPUS and 4 publications nationally accredited. He is registered as Member of Commission VI Division of Organizational Development and Training the Indonesian Veterinary Medical Association (IVMA).

Prof. Dr. Mustofa Helmi Effendi, drh., DTAPH. was officially inaugurated as the 524th Professor of Universitas Airlangga (UNAIR) is Professor in Veterinary Epidemiology Head of $D$ i v i s i o $n$ of Veterinary Public Health, Faculty of Veterinary Medicine, U n i v e r s i t a s Airlangga; His research focus is in the fields of Veterinary Epidemiology, AMR, Biomaterials and Good Laboratory Practice (animal ethics). A total of $\mathrm{H}$-index 13, citations 379, 58 publications indexed by SCOPUS. $\mathrm{He}$ is registered as a member Idonesian Veterinary Medical Association (IVMA).

Muhammad Thohawi Elziyad Purnama, DVM., M.Sc. is a lecturer at the Department of Veterinary Anatomy, Faculty of Veterinary Medicine, Universitas Airlangga. His research focus is in the fields of anatomy, physiology, biomaterials and animal ethics. A total of 22 publications indexed by SCOPUS and 70 publications nationally accredited. He is registered as a member of the Federation Equestre Internationale (FEI) and the Indonesian Veterinary Medical Association (IVMA).

Faisal Fikri, DVM., M.vet. is a lecturer at the Department of Veterinary science, Faculty of Veterinary Medicine, Universitas Airlangga. His research focus is in the fields of phytochemistry, physiology, biomaterials and animal ethics. A total of 10 publications indexed by SCOPUS and 40 publications nationally accredited. He is registered as a member of the Indonesian Veterinary Medical Association (IVMA).

Cite this article: Sukmanadi M, Effendi MH, Fikri F, Purnama MTE. Role of Capsaicin in the Repair of Cellular Activity in Mice Liver Pharmacogn J. 2021;13(6)Suppl: 1573-1576. 